\title{
Elastic properties and plastic deformation of TiC- and VC-based alloys
}

Daniel Edström, Davide Sangiovanni, Lars Hultman, Ivan Petrov, J oseph E Greene and Valeriu Chirita

The self-archived postprint version of this journal article is available at Linköping University Institutional Repository (DiVA):

http:// urn.kb.se/ resolve?urn=urn:nbn:se:liu:diva- 145470

N.B.: When citing this work, cite the original publication.

Edström, D., Sangiovanni, D., Hultman, L., Petrov, I., Greene, J. E, Chirita, V., (2018), Elastic properties and plastic deformation of TiC- and VC-based alloys, Acta Materialia, 144, 376-385. https:// doi.org/ 10.1016/j.actamat.2017.10.047

Original publication available at:

https:// doi.org/ 10.1016/j.actamat.2017.10.047

Copyright: Elsevier

http:// www.elsevier.com/

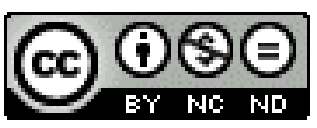


Elastic properties and plastic deformation of TiC- and VC-based pseudobinary alloys

D. Edström, ${ }^{1, *}$ D. G. Sangiovanni, ${ }^{1,2}$ L. Hultman, ${ }^{1}$ Ivan Petrov, ${ }^{1,3}$ J. E. Greene, ${ }^{1,3}$ and V. Chirita $^{1}$

${ }^{1}$ Department of Physics, Chemistry, and Biology (IFM)

Linköping University, SE-58183 Linköping, Sweden

${ }^{2}$ ICAMS, Ruhr-Universität Bochum, D-44801 Bochum, Germany

${ }^{3}$ Frederick Seitz Materials Research Laboratory and the Materials Science Department, University of Illinois at Urbana-Champaign, Urbana, Illinois 61801, USA

\section{Abstract}

Transition-metal (TM) carbides are an important class of hard, protective coating materials; however, their brittleness often limits potential applications. We use density functional theory to investigate the possibility of improving ductility by forming pseudobinary cubic $M^{l} M^{2} \mathrm{C}$ alloys, for which $M^{1}=\mathrm{Ti}$ or $\mathrm{V}$ and $M^{2}=\mathrm{W}$ or $\mathrm{Mo}$. The alloying elements are chosen based on previous results showing improved ductility of the corresponding pseudobinary nitride alloys with respect to their parent compounds. While commonly-used empirical criteria do not indicate enhanced ductility in the carbide alloys, calculated stress/strain curves along known slip systems, supported by electronic structure analyses, indicate ductile behavior for $\mathrm{VMoC}$. As $\mathrm{VMoC}$ layers are sheared along the $\langle 1 \overline{1} 0\rangle$ direction on $\{111\}$ planes, the stress initially increases linearly up to a yield point where the accumulated stress is partially dissipated. With further increase in strain, the stress increases again until fracture occurs. A similar mechanical behavior is observed for the corresponding TM nitride $\mathrm{VMoN}$, known to be a ductile ceramic material.[1] Thus, our results show that VMoC is a TM carbide alloy which may be both hard and ductile, i.e. tough.

Keywords: Carbides, density functional theory, elastic properties, ductility, toughness

*Corresponding author: Daniel Edström, Tel. 0046 13286693, Fax 004613137568 , daned@ifm.liu.se 


\section{Introduction}

The development of coatings possessing high hardness has been a key focus in materials science during the past few decades. [2] Hard coatings are commonly deposited on industrial components including architectural glass, tools, dies, and engine parts to provide scratch, thermal, oxidation, corrosion, abrasion, and wear resistance under extreme conditions, thereby enhancing component lifetimes and reducing costs. [3] Transition-metal (TM) carbides are among the hardest known compounds, with several binary carbides having hardnesses from 20 to $29 \mathrm{GPa}$. [4] In addition, TM carbides have very high melting points $\mathrm{T}_{\mathrm{m}}$, ranging up to $\sim 3983{ }^{\circ} \mathrm{C}$ for TaC. [4]

Increased hardness in ceramics has been achieved using a variety of approaches, all of which aim to reduce dislocation mobility. Examples include synthesis of nanoscale composites [5-7] and vacancy-induced hardening. [8-12] An additional method for improving hardness is tuning the valence-electron concentration (VEC) by alloying. It was shown by Jhi et al. [13] that a VEC of 8.4 yields maximum hardness in cubic single-crystal TM nitride and carbide alloys, as shear resistant metal-N/C d-p electronic states are fully occupied, while metallic d-d states are unoccupied. Hugosson et al. [14,15] employed VEC tuning to set the cubic and hexagonal structures of TM nitride and carbide alloys to equal energies, thus promoting the formation of stacking faults which increase hardness by hindering slip across the faults.

Hard materials typically do not provide facile response to plastic deformation. This limits their ability to dissipate stresses by plastic flow, and results in crack formation and propagation leading to brittle failure. Ceramics, such as TM nitrides and carbides, are inherently brittle. [16,17] Consequently, modern hard ceramic thin-film coatings are prone to brittle failure, especially during use on cutting tools. $[18,19]$ For applications, it 
is thus a priority to design coating materials which, in addition to being hard, are also ductile. The combination of hardness and ductility in a material is referred to as toughness.

In previous $a b$ initio studies, [20,21] we predicted that ordered cubic $\operatorname{Ti}_{0.5} \mathrm{Mo}_{0.5} \mathrm{~N}, \mathrm{Ti}_{0.5} \mathrm{~W}_{0.5} \mathrm{~N}, \mathrm{~V}_{0.5} \mathrm{Mo}_{0.5} \mathrm{~N}$, and $\mathrm{V}_{0.5} \mathrm{~W}_{0.5} \mathrm{~N}$ alloys are not only harder, but also significantly more ductile than their parent binaries, TiN and VN. This was explained as being due to an increased VEC leading to higher occupancy of metallic states at the Fermi level. The higher VEC not only preserves the strong $M e-\mathrm{N}$ bonds found in TM nitride binaries, but enables the formation of stronger $M e-M e$ bonds compared to parent $\mathrm{TiN}$ and VN compounds. Overall, higher VEC values lower shear resistance and promote dislocation glide, thus leading to increased ductility. The effect was shown to occur irrespective of the degree of ordering on the metallic sublattice. [22]

Experimental verification of the above predictions was recently provided by synthesis and physical property determinations of cubic single-crystal $\mathrm{V}_{0.5} \mathrm{Mo}_{0.5} \mathrm{~N}_{\mathrm{y}}(0.55$ $<\mathrm{y}<1$ ) thin films. [1,12] Stoichiometric VMoN alloys were found to be harder than VN, [1] and the hardness of $\mathrm{VMoN}_{\mathrm{y}}$ films increased monotonically by reducing the $\mathrm{N}$ content y from 1 to 0.55 . [12] Moreover, severe nanoindentation tests using a sharp cube-corner tip penetrating $1000 \AA$ into the substrate demonstrated that, while VN and TiN films exhibit extensive crack formation, $\mathrm{V}_{0.5} \mathrm{Mo}_{0.5} \mathrm{~N}$ films never crack. [1,12] In fact, indented VMoN samples display material pile-up, due to plastic flow, in regions adjacent to the indents; a behavior which is characteristic of ductile materials. As-deposited VMoN films grown at $\mathrm{T}_{\mathrm{s}}>700{ }^{\circ} \mathrm{C}$ exhibited no evidence of ordering on the metal sublattice; in contrast, $\mathrm{V}_{0.6} \mathrm{~W}_{0.4} \mathrm{~N}$ films grown at $600{ }^{\circ} \mathrm{C}$ and $700{ }^{\circ} \mathrm{C}$ exhibited a CuPt-type structrure on the metal sublattice with alternating V-rich and W-rich planes along <111> [23] 
Here, we report the results of $a b$ initio density functional theory (DFT) calculations and electronic structure analyses investigating the effects of VEC tuning on ductility enhancements in TiC- and VC-based cubic pseudobinary solid solutions, through alloying with $\mathrm{WC}$ and MoC. We calculate alloy free energies of formation as a function of metal composition, surface formation energies, elastic constants, and estimate hardness via models based on first-principles results. We also determine stress/strain curves along the $\{110\}\langle 1 \overline{1} 0\rangle$ and $\{111\}\langle 1 \overline{1} 0\rangle$ slip systems, which have been shown to be operative in TM carbides at room temperature, [24,25] in order to probe ductility enhancement in these pseudobinary systems.

\section{Computational details}

The Vienna ab initio simulation package (VASP) [26] is used to perform DFT calculations within the generalized gradient approximation of Perdew, Burke, and Ernzerhof (GGA-PBE). [27] Electron/ion interactions are described using projectoraugmented wave potentials (PAW), [28] and total energies are minimized and converged to within $10^{-5} \mathrm{eV} /$ atom using an energy cut-off of $500 \mathrm{eV}$ for the plane-wave basis set. In all bulk structure calculations, the Brillouin zone is sampled following the Monkhorst-Pack scheme, [29] whereas slab calculations for determining surface energies are performed using k-point meshes centered at the $\Gamma$-point. We use k-point grids of varying density (specified below) depending upon the material property investigated.

Formation energies for cubic $M^{1}{ }_{1-x} M^{2}{ }_{x} \mathrm{C}$ solid solutions are calculated across the full composition range, $0 \leq \mathrm{x} \leq 1$, using the expression

$$
\Delta E_{c u b M_{1-x}^{1} M_{x}^{2} C}=E_{c u b M_{1-x}^{1} M_{x}^{2} C}-(1-x) E_{c u b M^{1} C}-x E_{\text {cub or hex } M^{2} C},
$$


in which $x$ is the fraction on the metal sublattice occupied by $M^{2}$ and $E$ is the energy per atom. $E$ values are obtained directly from VASP output using 6x6x6 k-point meshes and 64 atoms arranged in the $\mathrm{NaCl}$-structure (space group $F m \overline{3} m$ [30]) and the hexagonal WC-structure (space group $P \overline{6} m 2$ [31]) for the reference binaries $M^{l} \mathrm{C}$ and $M^{2} \mathrm{C}$, respectively. Energies per atom for pseudobinary carbides are calculated using $4 \times 4 \times 4 \mathrm{k}-$ points with atoms in the special quasi-random structure (SQS). [32,33] The number of atoms $n$ in our supercells is 64 for alloys with $M^{2}$ concentrations $\mathrm{x}=0.125,0.375,0.625$, and 0.875 . For alloys with $\mathrm{x}=0.25,0.5$, and $0.75, n=48$ atoms.

The Gibbs free energy of formation for the pseudobinary carbides at temperature $T$ is estimated by adding the configurational entropy contribution (per atom) within the mean-field approximation [34]:

$$
T S=-0.5 k_{B} T(x \ln x+(1-x) \ln (1-x)) .
$$

Elastic constants $\mathrm{C}_{11}, \mathrm{C}_{12}$, and $\mathrm{C}_{44}$ and bulk, shear, and Young's moduli (B, G, and E) are obtained by fitting calculated strain energy versus strain $\delta$ curves, with $|\delta| \leq$ 0.005. For disordered systems, which do not have cubic symmetry, the projected cubic elastic constants, obtained as averages following the method described in [22] and [35] are:

$$
\begin{aligned}
& \bar{C}_{11}=\frac{C_{11}+C_{22}+C_{33}}{3}, \\
& \bar{C}_{12}=\frac{C_{12}+C_{13}+C_{23}}{3}, \\
& \bar{C}_{44}=\frac{C_{44}+C_{55}+C_{66}}{3} .
\end{aligned}
$$

Isotropic elastic moduli, shear moduli, and Poisson ratios reported here are determined based upon the Voigt-Reuss-Hill approach [36]. For these calculations, the 
parent binary $M^{l} \mathrm{C}$ compounds have the $\mathrm{NaCl}$ (B1) structure, while the pseudobinary $M^{1}{ }_{0.5} M^{2}{ }_{0.5} \mathrm{C}$ alloys are arranged in both 64-atom cubic ordered $\mathrm{C \# 3}$ structures [37] and disordered 128-atom SQS structures. The C\#3 structure consists of alternating (111) metal sublattice planes containing $M^{1}: M^{2}$ fractions of $3: 1$ and $1: 3$, respectively. It is closely related to the CuPt-ordered structure in binary metals [38], as well as TiWN [39] and VWN [23] solid solutions, which consist of alternating $\{111\}$ cation planes that are either primarily $M^{1}$ or primarily $M^{2}$. However, while the CuPt structure is rhombohedral, the C\#3 structure is cubic. The SQS structure is designed to minimize short-range metalmetal position correlations among neighboring shells in order to simulate disordered solid solutions.

Binary and pseudobinary carbide hardnesses are estimated following the model proposed by Šimůnek. [40] For a binary compound,

$$
H=\left(\frac{\alpha}{\Omega}\right) b_{12} s_{12} e^{-\sigma f_{2}}
$$

for which $b_{12}$ is the number of bonds between atoms of types 1 and 2 in a unit cell of volume $\Omega ; \alpha(=1450)$ and $\sigma(=2.8)$ are fitted parameters. The factor $s_{12}$ describes the bond strength and is defined as

$$
s_{12}=\frac{\sqrt{e_{1} e_{2}}}{n_{1} n_{2} d_{12}}
$$

in which e is the ratio between the number of valence electrons and the atomic radius, obtained from reference [41], $n$ is the coordination number (for the $\mathrm{NaCl}$ structure, $n=$ 6 ), and $\mathrm{d}_{12}$ is the bond length between atoms 1 and 2. The factor $f_{2}$ in equation (3) is defined as 


$$
f_{2}=\left(\frac{e_{1}-e_{2}}{e_{1}+e_{2}}\right)^{2}
$$

For a pseudobinary compound, hardness is expressed as the geometric mean of the two binary compounds:

$$
H=\left(\frac{\alpha}{\Omega}\right) 2 \sqrt{b_{12} s_{12} b_{34} s_{34}} e^{-\sigma f_{4}},
$$

with

$$
f_{4}=1-\left[\frac{4\left(e_{1} e_{2} e_{3} e_{4}\right)^{\frac{1}{4}}}{e_{1}+e_{2}+e_{3}+e_{4}}\right]^{2}
$$

Additionally, we also calculate hardness according to the methods suggested by Chen et. al [42] and Tian et. al [43], which give the hardness as

$$
H=2\left(k^{2} G\right)^{0.585}-3
$$

and

$$
H=0.92 k^{1.137} G^{0.708},
$$

respectively, with $\mathrm{k}=\mathrm{G} / \mathrm{B}$.

Surface energies are determined from the expression

$$
E_{\text {surf }}=0.5 *\left(E_{\text {slab }}-E_{\text {bulk }}\right) / S
$$

for which $E_{\text {slab }}$ is the energy of a (100)-, (110)-, or (111)-oriented surface slab, Ebulk is the energy of an equivalent slab in bulk $M^{1} M^{2} \mathrm{C}$, and $\mathrm{S}$ is the slab surface area. The factor 0.5 arises due to the fact that each slab has two surfaces. Since stoichiometric 111-oriented TM carbide slabs are polar, calculated 111 surface energies are averaged over metal- and carbon-terminated surfaces, and calculated accounting for dipole corrections which 
eliminate the discontinuity in the electrostatic potential at supercell vertical boundaries, as described in [44]. For pseudobinary alloys, surface energies are calculated with metal ions distributed randomly on the metal sublattice as well as in the C\#3 arrangement. In the latter case, the surface energy is calculated for both $M^{1}$-rich and $M^{2}$-rich terminations. (100)- and (110)-oriented slabs consist of 4x4x4 atoms and six layers of vacuum, while (111)-oriented slabs with random metal distributions have $3 \times 4 \times 6$ atoms and nine vacuum layers. To capture the (111) ordering in the C\#3 structure, (111)-oriented slabs consist of 4x2x12 atoms and 18 vacuum layers. The Brillouin zone is sampled with 3x3x1 k-point grids when calculating Eslab.

Stress/strain curves are obtained by sequentially straining the binary and pseudobinary carbides at intervals of $1 \%$ up to a maximum of $20 \%$ strain along the $\{110\}\langle 1 \overline{1} 0\rangle$ and $\{111\}\langle 1 \overline{1} 0\rangle$ slip systems. During each step, all ions are allowed to fully relax while maintaining the supercell shape fixed. A detailed description of our approach for carrying out the stress/strain calculations and for our choice of supercell configurations can be found in reference [45]. The Brillouin zone is sampled using $4 \times 4 \times 4$ k-points. For the $\{111\}\langle 1 \overline{1} 0\rangle$ slip system in VC and VWC, the VASP flag SYMPREC, which determines the accuracy of ion positions, was reduced to $1 \times 10^{-6}$ in order to reach convergence

\section{Results and discussion}

\subsection{Formation energies}

Pseudobinary TM carbide formation energies, calculated at $\mathrm{T}=0 \mathrm{~K}$, for SQS structures with respect to the energies of constituent binaries, are presented in Figure 1. The energies per atom determined for the two reference binary compounds are presented in Table 1. All pseudobinary formation energies are obtained with respect to 
mixing cubic $M^{l} \mathrm{C}$ with both cubic $M^{2} \mathrm{C}$ and hexagonal $M^{2} \mathrm{C}$ binary carbides (see equation (1)). The results show that $0 \mathrm{~K}$ formation energies for all cubic pseudobinary alloys are negative with respect to their cubic parent compounds, over the entire composition range, indicating thermodynamic stability against phase separation into cubic $M^{l} \mathrm{C}$ and $M^{2} \mathrm{C}$ phases. In contrast, formation energies at $0 \mathrm{~K}$ for cubic pseudobinary carbide alloys (except highly Ti-rich TiWC) are positive with respect to mixing cubic $M^{l} \mathrm{C}$ and hexagonal $M^{2} \mathrm{C}$, indicating that phase separation into cubic $M^{l} \mathrm{C}$ and hexagonal $M^{2} \mathrm{C}$ is thermodynamically favored. However, the precipitation of hexagonal $M^{2} \mathrm{C}$ in a cubic $M^{l} M^{2} \mathrm{C}$ host lattice is expected to be preceded by $M^{l} M^{2} \mathrm{C}$ decomposing via a spinodal mechanism into cubic $M^{l} \mathrm{C}$ and $M^{2} \mathrm{C}$, which is not thermodynamically favored. Consequently, our results indicate metastable cubic ternary carbide alloys can be synthesized by highly non-equilibrium methods such as physical vapor deposition. 

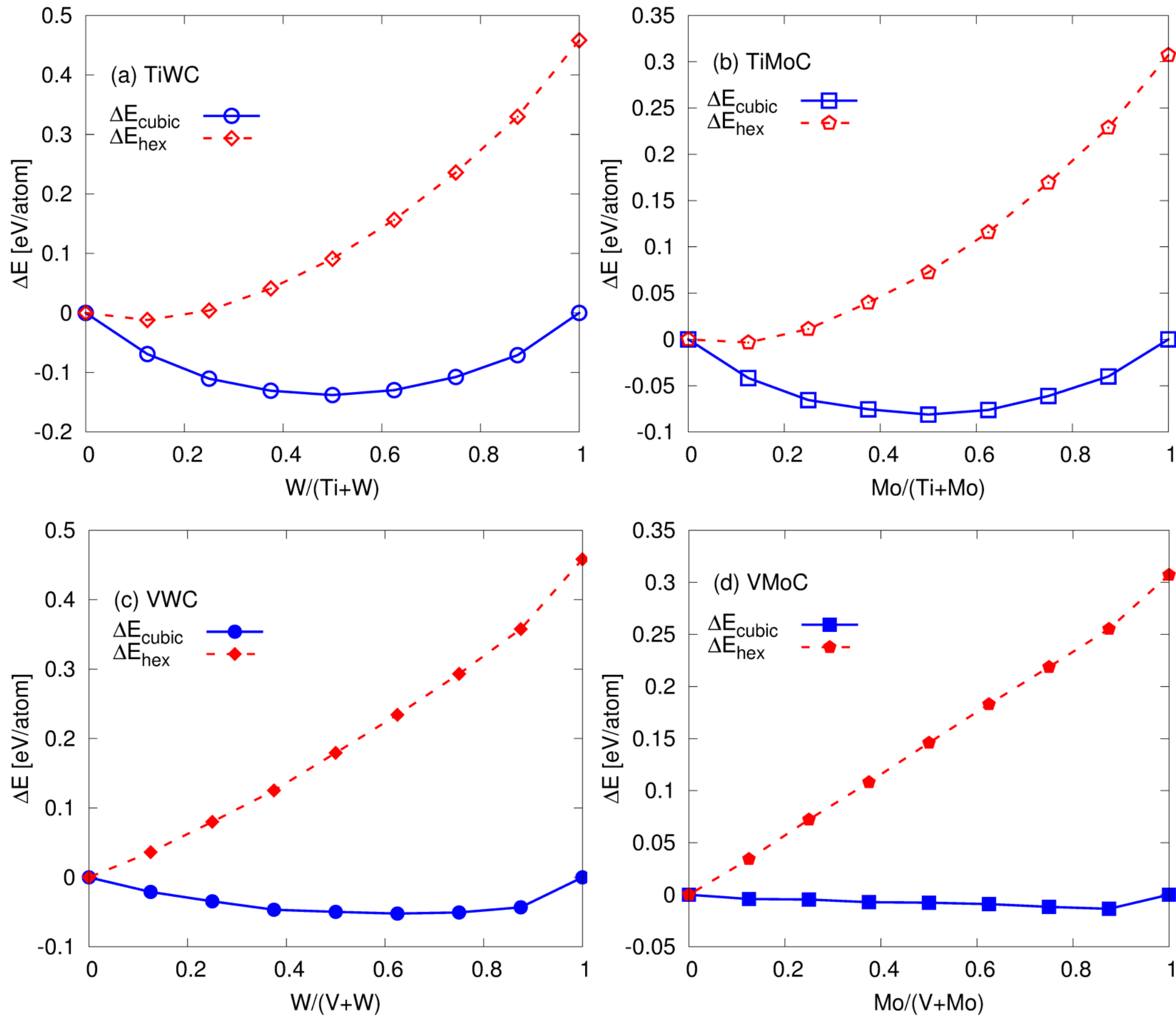

Figure 1. Formation energies $\triangle \mathrm{E}$ at $0 \mathrm{~K}$ of SQS-structure (a) TiWC, (b) TiMoC, (c) VWC, and (d) VMoC as a function of alloy compostion. The blue symbols indicate formation energies calculated with respect to cubic $(\mathrm{Ti}, \mathrm{V}) \mathrm{C}$ and $(\mathrm{W}, \mathrm{Mo}) \mathrm{C}$, whereas the red symbols indicate formation energies with respect to cubic $(\mathrm{Ti}, \mathrm{V}) \mathrm{C}$ and hexagonal $(\mathrm{W}, \mathrm{Mo}) \mathrm{C}$. 


\begin{tabular}{|r|c|c|}
\hline \multirow{2}{*}{} & \multicolumn{2}{|c|}{$\begin{array}{c}\text { Energy/atom } \\
\text { [eV/atom] }\end{array}$} \\
\cline { 2 - 3 } & B1 & Hexagonal WC structure \\
\hline TiC & -9.263 & - \\
VC & -9.472 & - \\
WC & -10.802 & -11.260 \\
MoC & -9.873 & -10.180 \\
\hline
\end{tabular}

Table 1. Calculated energies per atom at $\mathrm{T}=0 \mathrm{~K}$ for reference binary $\mathrm{TM}$ carbide compounds.

TiWC thin films have previously been synthesized between $\sim 5$ and $\sim 36$ at. $\%$ $\mathrm{W}$ on the metal sublattice using chemical vapor deposition at a temperature $\mathrm{T}_{\mathrm{s}}=1323 \mathrm{~K}$. [46] Calculated Gibbs free energies of formation for cubic $\mathrm{Ti}_{1-\mathrm{x}} \mathrm{W}_{\mathrm{x}} \mathrm{C}$, as well as $\mathrm{Ti}_{1 \text { - }}$ ${ }_{x} \mathrm{Mo}_{\mathrm{x}} \mathrm{C}, \mathrm{V}_{1-\mathrm{x}} \mathrm{W}_{\mathrm{x}} \mathrm{C}$, and $\mathrm{V}_{1-\mathrm{x}} \mathrm{Mo}_{\mathrm{x}} \mathrm{C}$, vs. $\mathrm{x}$ at $1323 \mathrm{~K}$ are presented in Figure 2. The entropic term, equation (2), decreases the free energy of formation below values calculated at $0 \mathrm{~K}$, which results in Ti-based cubic solid solutions having negative Gibbs' free energies of formation relative to hexagonal $M^{2} C$ at low $M^{2} C$ concentrations, indicating thermodynamic stability at $\mathrm{T}_{\mathrm{s}}=1323 \mathrm{~K}$ with $M^{2} C$ fractions below 25 mole $\%$ for $\mathrm{Ti} M^{2} \mathrm{C}$. Since the analysis of the mechanical properties of these compounds focuses on $M^{1}{ }_{0.5} M^{2}{ }_{0.5} C$ alloys in 64-atom C\#3 and 128-atom SQS structures, we also calculate formation energies at $\mathrm{T}=0 \mathrm{~K}$ and formation Gibbs' free energies at $\mathrm{T}=1323 \mathrm{~K}$ using these supercells. The results are presented in Table 2. 

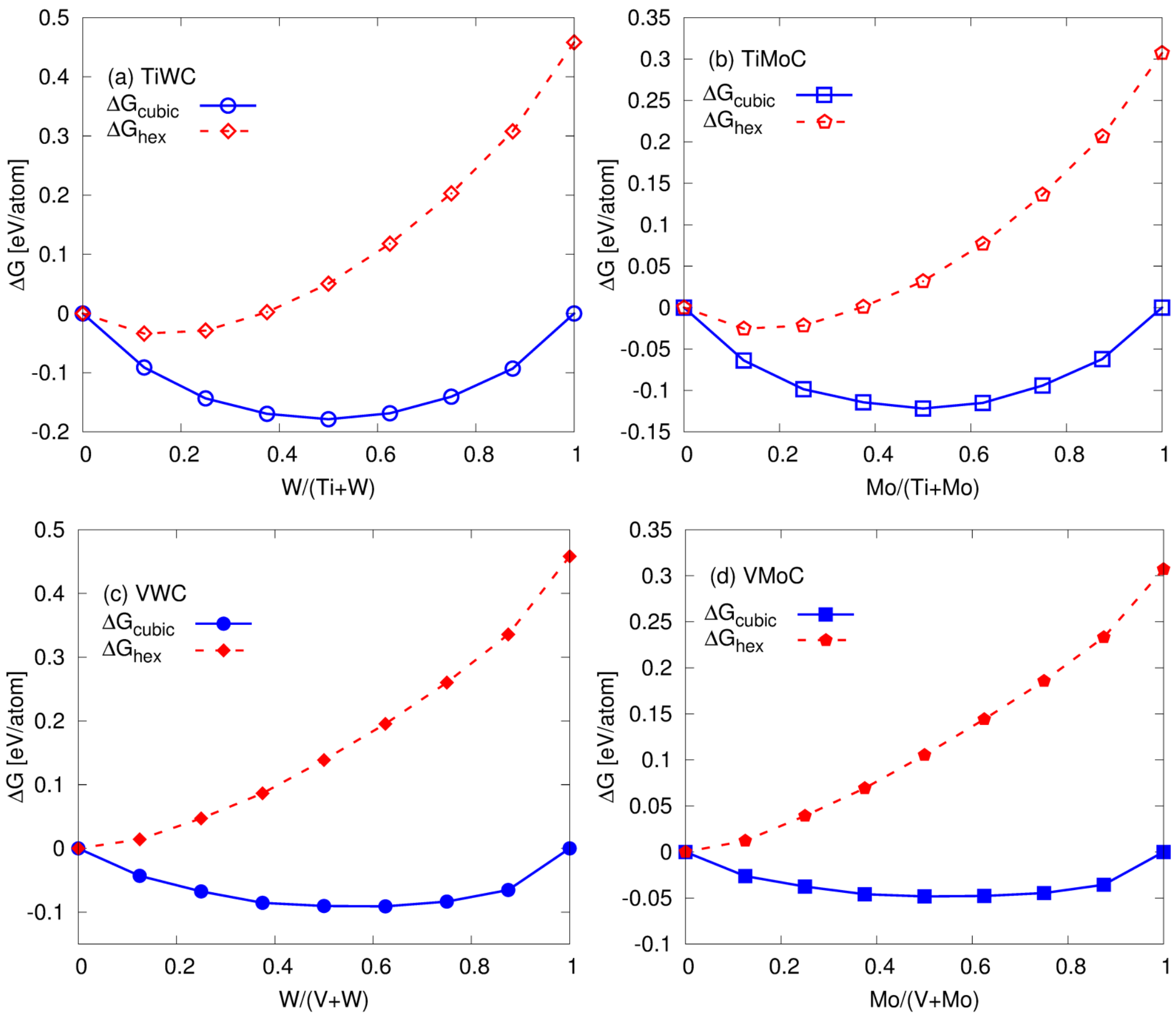

Figure 2. Gibbs' formation free energies $\Delta \mathrm{G}$ at $1323 \mathrm{~K}$ of SQS-structure (a) TiWC, (b) TiMoC, (c) VWC, and (d) VMoC. The blue symbols indicate $\Delta \mathrm{G}$ values calculated with respect to cubic $(\mathrm{Ti}, \mathrm{V}) \mathrm{C}$ and $(\mathrm{W}, \mathrm{Mo}) \mathrm{C}$. The red symbols indicate $\Delta \mathrm{G}$ values with respect to cubic $(\mathrm{Ti}, \mathrm{V}) \mathrm{C}$ and hexagonal $(\mathrm{W}, \mathrm{Mo}) \mathrm{C}$. 


\begin{tabular}{|r|c|c|c|c|c|}
\hline & \multirow{2}{*}{$\begin{array}{c}\text { Atomic } \\
\text { Arrangement }\end{array}$} & \multicolumn{4}{|c|}{$\begin{array}{c}\text { Formation energy } \\
\text { [eV/atom] }\end{array}$} \\
\cline { 3 - 6 } & & Relative to cubic $M^{2} \mathrm{C}$ & Relative to hexagonal $M^{2} \mathrm{C}$ \\
\cline { 3 - 6 } & $\mathrm{C \# 3}$ & -0.158 & -0.198 & 0.072 & 0.031 \\
$\mathrm{Ti}_{0.5} \mathrm{~W}_{0.5} \mathrm{C}$ & $\mathrm{SQS}$ & -0.137 & -0.178 & 0.092 & 0.051 \\
$\mathrm{Ti}_{0.5} \mathrm{~W}_{0.5} \mathrm{C}$ & $\mathrm{C \# 3}$ & -0.102 & -0.142 & 0.052 & 0.011 \\
$\mathrm{Ti}_{0.5} \mathrm{Mo}_{0.5} \mathrm{C}$ & $\mathrm{SQS}$ & -0.080 & -0.121 & 0.073 & 0.033 \\
$\mathrm{Ti}_{0.5} \mathrm{Mo}_{0.5} \mathrm{C}$ & $\mathrm{C \# 3}$ & -0.048 & -0.181 & 0.181 & 0.141 \\
$\mathrm{~V}_{0.5} \mathrm{~W}_{0.5} \mathrm{C}$ & $\mathrm{SQS}$ & -0.051 & -0.178 & 0.178 & 0.137 \\
$\mathrm{~V}_{0.5} \mathrm{~W}_{0.5} \mathrm{C}$ & $\mathrm{C \# 3}$ & -0.015 & -0.055 & 0.139 & 0.098 \\
$\mathrm{~V}_{0.5} \mathrm{Mo}_{0.5} \mathrm{C}$ & $\mathrm{SQS}$ & -0.008 & -0.049 & 0.145 & 0.105 \\
$\mathrm{~V}_{0.5} \mathrm{Mo}_{0.5} \mathrm{C}$ & $\mathrm{S}$ &
\end{tabular}

Table 2. Calculated formation energies $(\mathrm{T}=0 \mathrm{~K})$ and formation Gibbs' free energies ( $\mathrm{T}=1323 \mathrm{~K}$ ) for C\#3 and SQS structure $M^{1}{ }_{0.5} M^{2}{ }_{0.5} \mathrm{C}$ alloys.

(100), (110), and (111) surface energies for $M^{l}{ }_{0.5} M^{2}{ }_{0.5} \mathrm{C}$ alloys and the parent compounds $\mathrm{TiC}, \mathrm{VC}$, and $\mathrm{MoC}$ are listed in Table 3. The pseudobinary surface energies are obtained for both a random metal atom distribution and $\mathrm{C \# 3}$ ordering. The polar (111) surface energies correspond to an average of metal and $\mathrm{C}$ terminations. In all cases, pseudobinary TM carbide surface energies are slightly lower than for the corresponding parent binaries $\mathrm{TiC}$ and $\mathrm{VC}$, and higher than for $\mathrm{MoC}$, but follow the same trend: (100) has the lowest surface energy, followed by (110), with (111) being the highest. Comparing the surface energies of $M^{1}$ - and $M^{2}$-rich (111) terminations for the C\#3 structure shows that $M^{2}$-rich terminations result in higher surface energies, indicative of stronger $M^{2}$-C than $M^{1}-\mathrm{C}$ bonds, with the difference being greatest for $M^{1}=\mathrm{Ti}$. For the (111) surface, values are presented with and without dipole-moment corrections. In slabs with random metal distributions, accounting for the dipole correction decreases the surface energy by approximately $0.2 \%$. Because the $\mathrm{C} \# 3$-structured slabs require more layers, the magnitude of the dipole correction is significantly smaller. With $M^{l}=\mathrm{Ti}$, including, or ignoring, the dipole correction does not alter the result to the third decimal place; thus, only one value is presented. 


\begin{tabular}{|c|c|c|c|}
\hline & \multicolumn{3}{|c|}{ Surface energies $\left[\mathrm{J} / \mathrm{m}^{2}\right]$} \\
\hline & $(100)$ & (110) & $(111)$ \\
\hline $\mathrm{TiC}$ & 1.629 & 3.459 & $5.525^{*}, 5.536$ \\
\hline $\mathrm{VC}$ & 1.201 & 2.988 & $4.370^{*}, 4.380$ \\
\hline $\mathrm{MoC}$ & 0.849 & 1.789 & 2.827 \\
\hline $\mathrm{Ti}_{0.5} \mathrm{~W}_{0.5} \mathrm{C}-$ random & 1.280 & 2.997 & $3.742 *, 3.751$ \\
\hline $\mathrm{Ti}_{0.5} \mathrm{~W}_{0.5} \mathrm{C}-\mathrm{C \# 3}$ & 1.337 & 2.960 & $3.665^{\mathrm{Ti}}, 4.525^{\mathrm{W}}$ \\
\hline $\mathrm{Ti}_{0.5} \mathrm{Mo}_{0.5} \mathrm{C}$ - random & 1.224 & 2.915 & $3.767^{*}, 3.776$ \\
\hline $\mathrm{Ti}_{0.5} \mathrm{Mo}_{0.5} \mathrm{C}-\mathrm{C \# 3}$ & 1.254 & 2.852 & $3.754^{\mathrm{Ti}}, 4.401^{\mathrm{Mo}}$ \\
\hline $\mathrm{V}_{0.5} \mathrm{~W}_{0.5} \mathrm{C}-$ random & 1.071 & 2.531 & $3.060 *, 3.066$ \\
\hline $\mathrm{V}_{0.5} \mathrm{~W}_{0.5} \mathrm{C}-\mathrm{C} \# 3$ & 1.129 & 2.533 & $3.267^{\mathrm{V}}, 3.552^{\mathrm{W}}, 3.555^{\mathrm{W}}$ \\
\hline $\mathrm{V}_{0.5} \mathrm{Mo}_{0.5} \mathrm{C}-$ random & 1.010 & 2.462 & $3.167 *, 3.175$ \\
\hline $\mathrm{V}_{0.5} \mathrm{Mo}_{0.5} \mathrm{C}-\mathrm{C} \# 3$ & 1.021 & 2.428 & $3.406^{\mathrm{V}}, 3.460^{\mathrm{Mo} *}, 3.464^{\mathrm{Mo}}$ \\
\hline
\end{tabular}

Table 3. Calculated relaxed surface energies for pseudobinary TM-carbide alloys and parent binary compounds. The (111) surface energies indicated with superscripts, corresponding to metal surface terminations, are C\#3 ordered; values labelled with asterisks account for dipole corrections (see text).

\subsection{Elastic properties}

The elastic properties of $M^{1} 0.5 M^{2}{ }_{0.5} \mathrm{C}$ alloys and the parent binary compounds $\mathrm{TiC}$ and $\mathrm{VC}$ are listed in Table 4. For TiC-based pseudobinary alloys, other than SQS $\mathrm{Ti}_{0.5} \mathrm{Mo}_{0.5} \mathrm{C}$, the bulk modulus B increases by approximately $14-20 \%$ upon alloying with $M^{2} \mathrm{C}$, indicating enhanced strength. The elastic and shear moduli, E and G, also increase upon alloying, and the Poisson ratio $v$ decreases; all results are indicative of enhanced stiffness. The exception to these trends is SQS-disordered $\mathrm{Ti}_{0.5} \mathrm{Mo}_{0.5} \mathrm{C}$. For this structure, E, G, and $v$ are essentially unchanged with respect to the values obtained for TiC. Calculated hardnesses, obtained using the Šimůnek method and presented in Table 5, show an increase in TiC-based pseudobinaries, compared to $\mathrm{TiC}$, of approximately $16 \%$, consistent with increases in elastic and shear moduli, as well as the reduction in the Poisson ratio. The Chen and Tian methods do not show a corresponding increase, instead they predict hardnesses comparable to TiC. 


\begin{tabular}{|r|c|c|c|c|c|c|c|c|c|c|}
\hline & $\begin{array}{c}\text { Atomic } \\
\text { arrangement }\end{array}$ & $\begin{array}{c}B \\
{[\mathrm{GPa}]}\end{array}$ & $\begin{array}{c}E \\
{[\mathrm{GPa}]}\end{array}$ & $\begin{array}{c}G \\
{[\mathrm{GPa}]}\end{array}$ & $v$ & $\begin{array}{c}\bar{C}_{44} \\
{[\mathrm{GPa}]}\end{array}$ & $\begin{array}{c}\bar{C}_{11} \\
{[\mathrm{GPa}]}\end{array}$ & $\begin{array}{c}\bar{C}_{12} \\
{[\mathrm{GPa}]}\end{array}$ & $\begin{array}{c}\bar{C}_{12}-\bar{C}_{44} \\
{[\mathrm{GPa}]}\end{array}$ & $G / B$ \\
\hline $\mathrm{TiC}$ & $\mathrm{B} 1$ & 270 & 445 & 182 & 0.317 & 165 & 550 & 130 & -35 & 0.674 \\
\hline $\mathrm{VC}$ & $\mathrm{B} 1$ & 318 & 523 & 222 & 0.285 & 185 & 706 & 124 & -61 & 0.698 \\
\hline $\mathrm{MoC}$ & $\mathrm{B} 1$ & 352 & 416 & 167 & 0.329 & 126 & 691 & 182 & 56 & 0.476 \\
\hline $\mathrm{Ti}_{0.5} \mathrm{~W}_{0.5} \mathrm{C}$ & $\mathrm{C \# 3}$ & 324 & 526 & 224 & 0.283 & 184 & 725 & 124 & -60 & 0.691 \\
\hline $\mathrm{Ti}_{0.5} \mathrm{~W}_{0.5} \mathrm{C}$ & $\mathrm{SQS}$ & 312 & 474 & 196 & 0.305 & 172 & 632 & 152 & -19 & 0.628 \\
\hline $\mathrm{Ti}_{0.5} \mathrm{Mo}_{0.5} \mathrm{C}$ & $\mathrm{C} \# 3$ & 308 & 481 & 200 & 0.302 & 171 & 644 & 140 & -31 & 0.648 \\
\hline $\mathrm{Ti}_{0.5} \mathrm{Mo}_{0.5} \mathrm{C}$ & $\mathrm{SQS}$ & 295 & 442 & 180 & 0.318 & 163 & 575 & 155 & -7 & 0.610 \\
\hline $\mathrm{V}_{0.5} \mathrm{~W}_{0.5} \mathrm{C}$ & $\mathrm{C} 33$ & 338 & 482 & 200 & 0.302 & 169 & 681 & 167 & -2 & 0.592 \\
\hline $\mathrm{V}_{0.5} \mathrm{~W}_{0.5} \mathrm{C}$ & $\mathrm{SQS}$ & 328 & 465 & 192 & 0.309 & 161 & 659 & 162 & 1 & 0.584 \\
\hline $\mathrm{V}_{0.5} \mathrm{Mo}_{0.5} \mathrm{C}$ & $\mathrm{C \# 3}$ & 332 & 469 & 194 & 0.307 & 164 & 663 & 167 & 3 & 0.583 \\
\hline $\mathrm{V}_{0.5} \mathrm{Mo}_{0.5} \mathrm{C}$ & $\mathrm{SQS}$ & 317 & 454 & 186 & 0.313 & 156 & 637 & 158 & 1 & 0.586 \\
\hline
\end{tabular}

Table 4. Calculated mechanical properties for pseudobinary $M_{0.5}^{1} M^{2}{ }_{0.5} \mathrm{C}$ carbide alloys and their parent compounds. $B, E$, and $G$ are the bulk, elastic, and shear moduli; $v$ is Poisson's ratio, and $\bar{C}_{44}, \bar{C}_{11}$, and $\bar{C}_{12}$ are the fundamental cubic elastic constants. 


\begin{tabular}{|r|c|c|c|c|}
\hline & \multirow{2}{*}{$\begin{array}{c}\text { Atomic } \\
\text { arrangement }\end{array}$} & \multicolumn{3}{|c|}{$\begin{array}{c}|c| \\
\text { [GPa] }\end{array}$} \\
\cline { 3 - 5 } & & Simunek & Chen & Tian \\
\hline $\mathrm{TiC}$ & $\mathrm{B} 1$ & 16.3 & 23.5 & 23.4 \\
\hline $\mathrm{VC}$ & $\mathrm{B} 1$ & 25.6 & 28.0 & 28.0 \\
\hline $\mathrm{MoC}$ & $\mathrm{B} 1$ & 22.8 & 13.7 & 14.8 \\
\hline $\mathrm{Ti}_{0.5} \mathrm{~W}_{0.5} \mathrm{C}$ & $\mathrm{C \# 3}$ & 18.9 & 27.8 & 27.9 \\
\hline $\mathrm{Ti}_{0.5} \mathrm{~W}_{0.5} \mathrm{C}$ & $\mathrm{SQS}$ & 18.8 & 22.5 & 22.8 \\
\hline $\mathrm{Ti}_{0.5} \mathrm{Mo}_{0.5} \mathrm{C}$ & $\mathrm{C \# 3}$ & 18.9 & 23.8 & 24.0 \\
\hline $\mathrm{Ti}_{0.5} \mathrm{Mo}_{0.5} \mathrm{C}$ & $\mathrm{SQS}$ & 18.9 & 20.4 & 20.7 \\
\hline $\mathrm{V}_{0.5} \mathrm{~W}_{0.5} \mathrm{C}$ & $\mathrm{C} \# 3$ & 23.7 & 21.0 & 21.6 \\
\hline $\mathrm{V}_{0.5} \mathrm{~W}_{0.5} \mathrm{C}$ & $\mathrm{SQS}$ & 23.6 & 20.2 & 20.7 \\
\hline $\mathrm{V}_{0.5} \mathrm{Mo}_{0.5} \mathrm{C}$ & $\mathrm{C \# 3}$ & 23.9 & 20.2 & 20.8 \\
\hline $\mathrm{V}_{0.5} \mathrm{Mo}_{0.5} \mathrm{C}$ & $\mathrm{SQS}$ & 23.8 & 19.8 & 20.3 \\
\hline
\end{tabular}

Table 5. Calculated hardnesses $H$ of C\#3-ordered and SQS $M^{I}{ }_{0.5} M^{2}{ }_{0.5} \mathrm{C}$ pseudobinary TM-carbide alloys and their parent compounds.

The bulk modulus of VC-based pseudobinaries also increases with respect to the parent $\mathrm{VC}$ binary, except for disordered $\mathrm{V}_{0.5} \mathrm{Mo}_{0.5} \mathrm{C}$ for which $B$ is essentially equal to that of VC. However, in contrast to TiC-based pseudobinaries, shear and elastic moduli decrease compared to the parent VC binary, while the Poisson ratio increases, suggesting a reduction in stiffness. Alloy hardnesses calculated using the Šimůnek method are reduced compared to VC (Table 5). However, the reduction is relatively small, $<10 \%$, and VC-based alloys are predicted to be harder than both $\mathrm{TiC}$ and TiC-based pseudobinaries. The Chen and Tian methods predict larger reductions, $\sim 25 \%$, suggesting that VC-based peudobinaries are softer than TiC and TiC-based pseudobinaries.

The tendency toward ductility in materials systems is sometimes estimated via the empirical criteria of Pugh [47] and Pettifor [48], which associate ductile behavior with $\mathrm{G} / \mathrm{B}<0.5$ and a Cauchy pressure $\left(\mathrm{C}_{12}-\mathrm{C}_{44}\right)>0$, respectively. Results for the $M_{0.5}^{1} M^{2}{ }_{0.5} \mathrm{C}$ alloys and parent $M^{l} \mathrm{C}$ binaries are presented in Figure 3. Disordered VWC and both ordered and disordered lattice arrangements of $\mathrm{VMoC}$ are the only pseudobinaries which have slightly positive Cauchy pressures, while all compounds 
exhibit $\mathrm{G} / \mathrm{B}$ ratios higher than 0.5 . However, since these criteria are purely empirical and plastic deformation occurs primarily beyond the yield point, a more quantitative investigation requires an analysis of stress/strain relationships along active slip systems. 


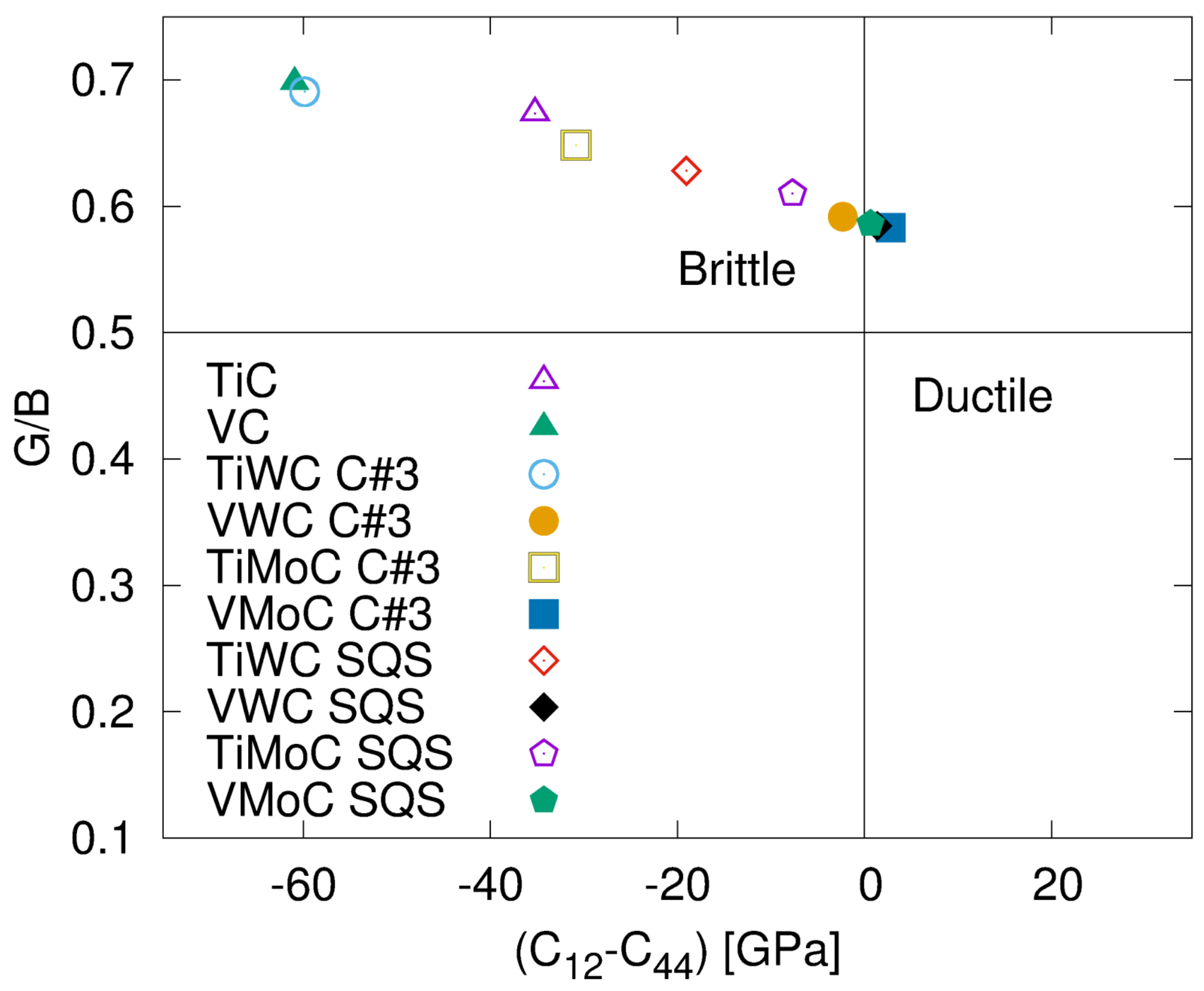

Figure 3. Calculated shear-to-bulk moduli $(\mathrm{G} / \mathrm{B})$ ratios vs. the Cauchy pressure, $\left(\mathrm{C}_{12}-\mathrm{C}_{44}\right)$, of the parent TM carbides TiC and VC and pseudobinary alloys formed with WC and MoC. Empirical criteria of Pugh [42] and Pettifor [43] associate ductile behavior with $\mathrm{G} / \mathrm{B}<0.5$ and $\left(\mathrm{C}_{12}-\mathrm{C}_{44}\right)>0$, respectively. 


\subsection{Stress/strain relationships}

Figure 4(a) presents stress/strain curves for the binary and ordered TM carbide alloys along the $\{110\}\langle 1 \overline{1} 0\rangle$ slip system, known to be active in $\mathrm{TiC}$ at room temperature [49]. The stress/strain response is linear up to approximately 50\% strain for all carbide systems investigated; at which point, the stress reaches a maximum and begins to slowly decrease. The initial slope of the curves is the shear resistance. At elevated temperatures, $\{111\}\langle 1 \overline{1} 0\rangle$ becomes the active slip system in $\mathrm{TiC}$, due to an increased density of high-mobility electrons screening directional covalent bonds. [50] Thus, we also calculate stress/strain curves along this slip system. The results for the binary and ordered pseudobinary structures are shown in Figure 4(b). Upon straining, the stress in $\mathrm{TiC}$ and $\mathrm{VC}$ increases linearly, i.e. the compounds behave elastically, until fracture at 45 $48 \%$ strain. Neither the Ti-based alloys, nor VWC, exhibit yielding for strains $\leq 20 \%$. 

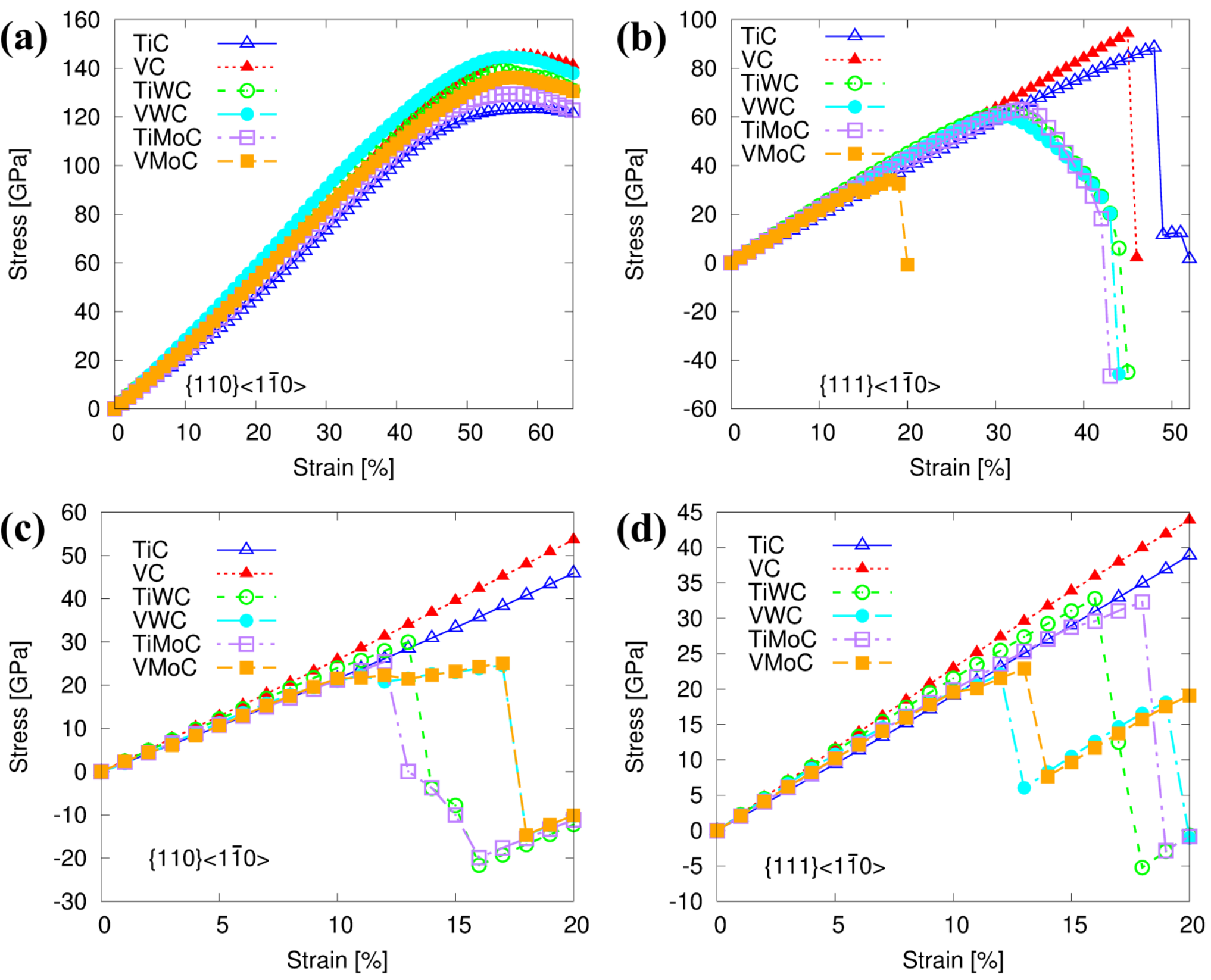

Figure 4. Stress/strain curves upon shearing along, (a) and (c), $\{110\}\langle 1 \overline{1} 0\rangle$ and, (b) and (d), $\{111\}\langle 1 \overline{1} 0\rangle$. The pseudobinary alloys have ordered atomic arrangements in (a)-(b), and disordered SQS atomic arrangements in (c)-(d). 
The VMoC stress/strain curve in Fig. 4(b) displays an unexpected feature. The stress/strain relationship remains linear up to $14 \%$ strain, above which the stress decreases until a linear stress/strain relationship is recovered at $15 \%$ and maintained up to $18-19 \%$, when fracture occurs. This type of behavior is similar to typical stress/strain relationships observed for ductile materials, in which a yield point, defined as the strain beyond which the material begins to deform plastically, is reached prior to fracture occurring.

Figure 5 shows calculated stress/strain curves for the ordered reference alloy $\mathrm{V}_{0.5} \mathrm{Mo}_{0.5} \mathrm{~N}$, which is known both experimentally [1] and theoretically [21] to be relatively ductile, together with $\mathrm{V}_{0.5} \mathrm{Mo}_{0.5} \mathrm{C}$ along the same slip systems. The primary slip system in TM nitrides is $\{110\}\langle 1 \overline{1} 0\rangle$, as for transition metal carbides, and slip along $\{111\}\langle 1 \overline{1} 0\rangle$ has also been demonstrated.[51] Stress/strain curves for VMoC and VMoN along the $\{110\}\langle 1 \overline{1} 0\rangle$ slip system are shown in Figure 5(a). The curves exhibit the same general features as for the TM carbide alloys in Fig 4; stress increases monotonically up to $\sim 50 \%$ strain, at which point it levels off and begins to decrease, with VMoN reaching a slightly higher stress. Figure 5(b) compares the stress/strain curves along the $\{111\}\langle 1 \overline{1} 0\rangle$ slip system. For VMoN, the stress increases linearly up to $20 \%$ strain, at which point it decreases slightly and levels off, before fracturing at $42 \%$ strain. This response is qualitatively similar to that of the VMoC alloy which fractures at a lower strain. The close resemblance in the features of the VMoC and VMoN $\{110\}\langle 1 \overline{1} 0\rangle$ stress/strain curves, and qualitative similarity between the $\{111\}\langle 1 \overline{1} 0\rangle$ stress/strain curves, indicates that $\mathrm{VMoC}$ is a candidate for a TM carbide alloy with increased toughness. 

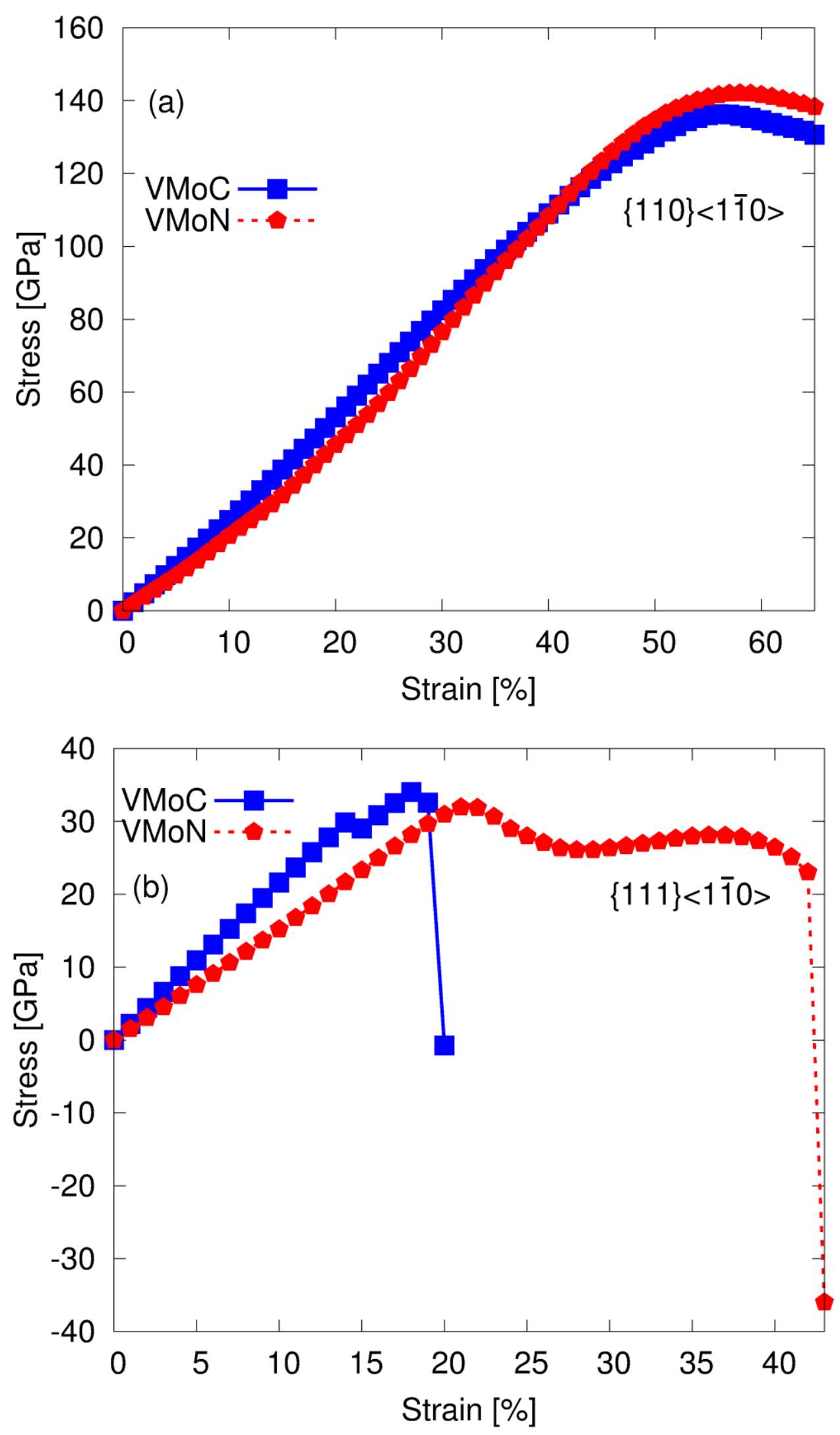

Figure 5. Stress/strain curves for VMoC (blue squares) and VMoN (red pentagons) along (a) $\{110\}<110\rangle$ and (b) $\{111\}<110>$ slip systems. 
We also calculate corresponding stress/strain curves for disordered SQS alloy structures along the $\{110\}\langle 1 \overline{1} 0\rangle$ and $\{111\}\langle 1 \overline{1} 0\rangle$ slip systems, Figures $4(\mathrm{c})$ and 4(d). For $\{110\}\langle 1 \overline{1} 0\rangle$, disordered VWC and VMoC yield at $11 \%$ strain and fracture at $18 \%$ strain, while disordered TiWC and TiMoC fracture at $14 \%$ and $13 \%$ strain, respectively, without exhibiting a yield point. A similar trend is observed along the $\{111\}\langle 1 \overline{1} 0\rangle$ slip system. The stress in disordered TiWC and TiMoC increases linearly until fracture at 18 and 19\% strain. Disordered VWC and VMoC yield at 13 and $14 \%$ strain; VWC then fractures at $20 \%$, but VMoC does not fracture at strains $\leq 20 \%$.

\subsection{Charge-density distributions}

The difference between the TM carbide compounds exhibiting a continuous linear stress/strain response prior to brittle fracture (TiWC, TiMoC, and VWC), and VMoC which displays yielding is further analyzed by examining charge-density distributions. Figure 6 shows $\mathrm{T}=0 \mathrm{~K}$ charge densities in the $(11 \overline{2})$ plane, i.e. orthogonal to the $\{111\}\langle 1 \overline{1} 0\rangle$ slip system, for ordered (C\#3) VWC and VMoC at 14, 15, 19, and $20 \%$ strain, which are the points immediately prior the first (15\%), and after the second (19\%), drops in stress observed for VMoC. At $14 \%$ strain, regions of increased charge density connect neighboring $\mathrm{V}$ and $\mathrm{C}$ atoms with $\mathrm{C}-\mathrm{V}-\mathrm{C}$ bonds in both $\mathrm{VWC}$ and VMoC. Figure 6 also reveals C-C and W-W bonds for VWC. The corresponding C-C and Mo-Mo bonds in $\mathrm{VMoC}$ do not form until $15 \%$ strain. At $19 \%$ strain, just prior to fracture, the newly formed C-C and Mo-Mo bonds are clearly visible in VMoC charge-density maps, as V$\mathrm{V}$ bonds begin to form as well. However, no significant changes are observed in VWC. At $20 \%$ strain, corresponding to VMoC fracture (Fig 4b), a new charge-density structure is observed, containing planes of strongly-bonded V-V and Mo-Mo atoms, with significantly weakened C-V and C-Mo bonds. In contrast, the charge density of VWC, 
which exhibits an approximately linear stress/strain response, is unchanged from that corresponding to $14 \%$ strain. Similar trends are observed for the charge density of SQS VMoC along the $\{111\}\langle 1 \overline{1} 0\rangle$ slip system, and are expected for the other disordered pseudobinaries which either exhibit yield points and/or deviate from linear stress/strain response. 

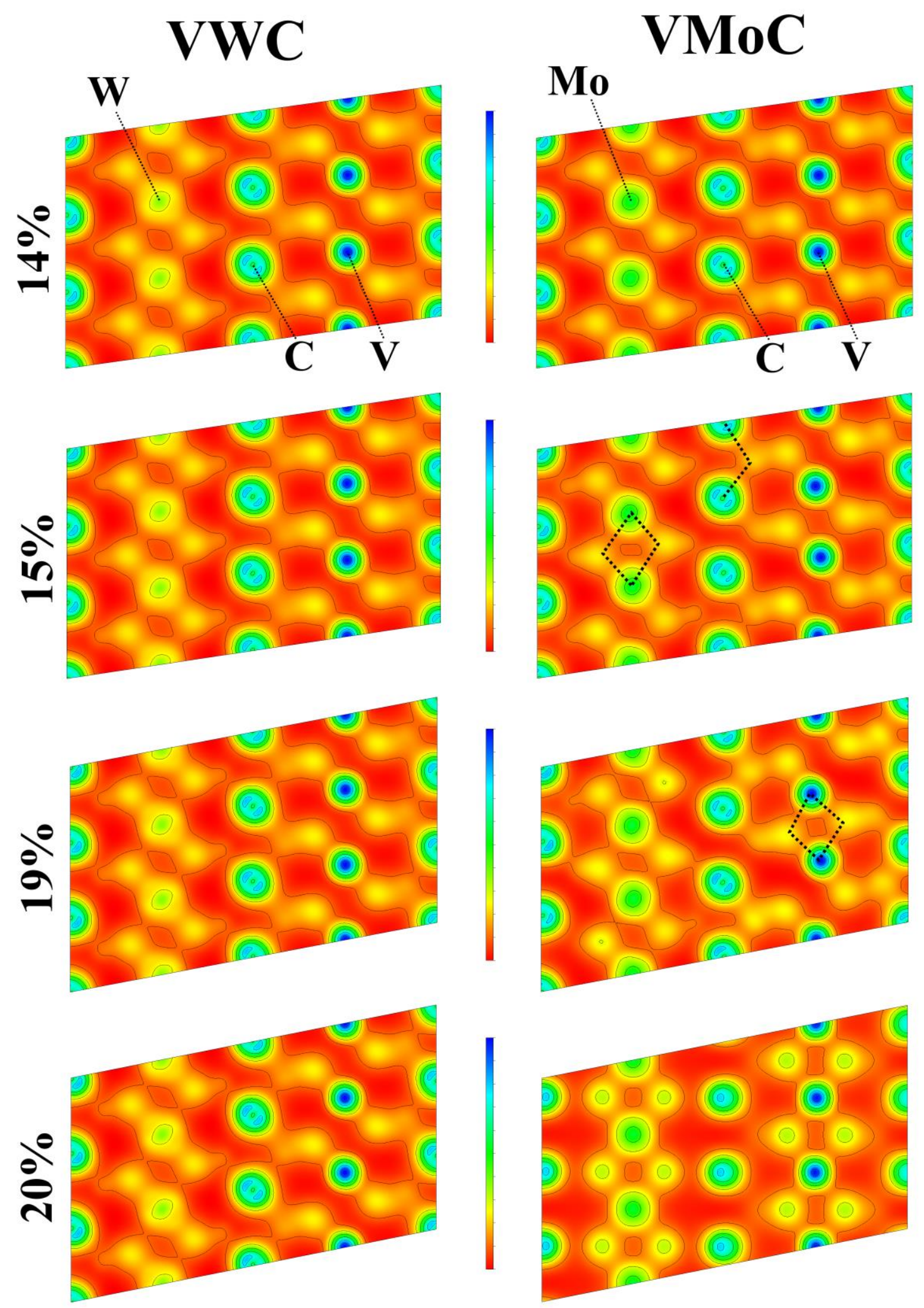

Figure 6. Charge density maps for the $(11 \overline{2})$ planes of C\#3 ordered VWC and VMoC under $14,15,19$ and $20 \%$ strain along the $\{111\}\langle 1 \overline{1} 0\rangle$ slip system at $\mathrm{T}=0 \mathrm{~K}$. The dotted lines highlight the formation of new bonds in $\mathrm{VMoC}$ as the material is strained. 
In ordered TM nitride alloys, electronic layering perpendicular to the applied shear strain was shown to be an important mechanism for toughness enhancement. [20,21,52] Thus, to complete the investigation of the elastic properties of TM carbides, we carry out similar analyses by calculating charge densities for the $\mathrm{C \# 3}$ ordered pseudobinary alloys and their parent binary compounds. For each materials system, we calculate the charge densities for the unstrained structure as well as at $10 \%$ tetragonal and trigonal strains, along [100] and [110], respectively. The results are shown in Figure 7 for the (001) plane. To facilitate interpretation of the maps, contour lines in charge density are drawn with a linear separation of $0.34 \mathrm{e}^{-} / \AA^{3}$. The charge densities of relaxed $\mathrm{TiC}$ and $\mathrm{VC}$ structures, Figure 7(a), exhibit strong ionic character with a high charge concentration surrounding the nuclei. W-C and Mo-C bonds present in the pseudobinary alloys have a more covalent character with delocalized charge, particularly around Mo and $\mathrm{W}$ nuclei. 

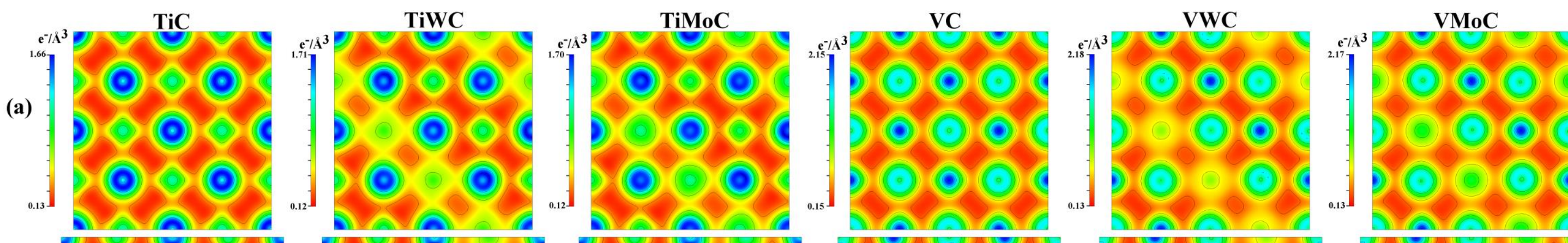

(b)
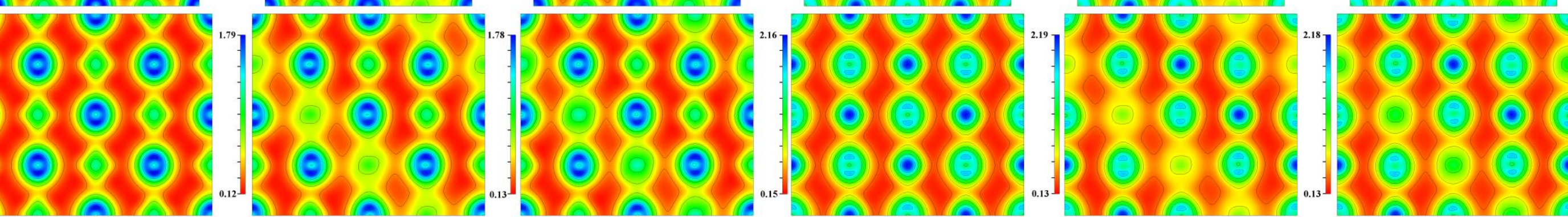

(c)
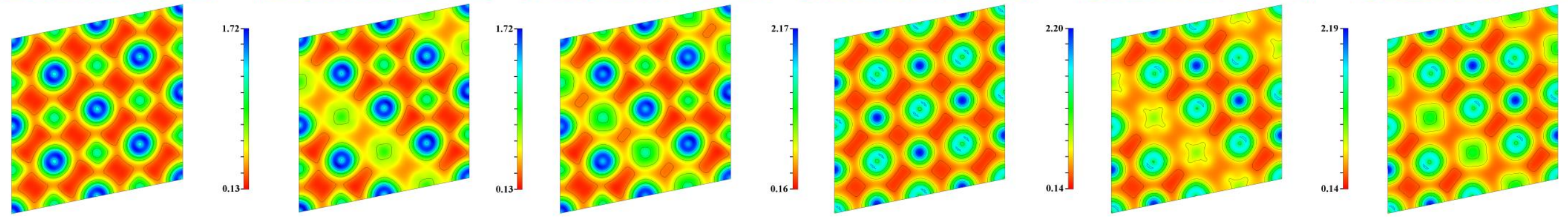

Figure 7. Charge density maps in $\mathrm{e}^{-} / \AA^{3}$ for the (001) plane of, from left to right, TiC, TiWC, TiMoC, $\mathrm{VC}, \mathrm{VWC}$, and $\mathrm{VMoC}$ at $\mathrm{T}=0 \mathrm{~K}$. Pseudobinary compounds are ordered in the $\mathrm{C} \# 3$ structure. (a) Unstrained, (b) tetragonal strain of $10 \%$, (c) trigonal strain of $10 \%$. 
When subjecting TiC or VC to a tetragonal strain of $10 \%$ along [100] at T $=0 \mathrm{~K}$, as shown in Figure 7(b), the bonds are weakened in the elongation direction, resulting in an atomic-layer stacking with reduced interfacial charge. Conversely, the charge densities obtained due to a 10\% trigonal strain along [110] (Figure 7(c)) are essentially the same as for the unstrained cases. For the $\mathrm{C \# 3}$ ordered pseudobinary alloys at $\mathrm{T}=0 \mathrm{~K}$, the $M^{1}-\mathrm{C}$ bonds are weakened upon tetragonal shear strain, but the $M^{2}-\mathrm{C}$ bond strength remains approximately constant. Additionally, the pseudobinary $M^{1} M^{2} \mathrm{C}$ alloys display a tendency to form alternating planes of high and low charge density along [1 $1 \overline{1} 0]$ directions, perpendicular to the applied strain upon trigonal shearing, as charge accumulates along $M^{2}$-containing planes which are thus characterized by strong metallic bonding. $M^{1}$-containing planes, however, display mixed ionic and covalent bonding. This is similar to the layered structure found in corresponding TM nitrides, and promotes a dual hard/ductile (i.e., tough) character. [20]

Disordered pseudobinary TM nitrides were also found to form layered structures perpendicular to the strain direction upon shearing. [22] Based on the similar charge density response of ordered carbide and nitride alloys, as discussed above, we expect equivalent layering formation leading to enhanced toughness in disordered TMC alloys as well.

\section{Conclusions}

We have carried out DFT calculations of the formation energies, elastic properties, and stress/strain curves along $\{110\}\langle 1 \overline{1} 0\rangle$ and $\{111\}\langle 1 \overline{1} 0\rangle$ slip systems, for cubic pseudobinary transition-metal carbide alloys TiWC, TiMoC, VWC, and VMoC. Hardness estimates based on reliable theoretical models indicate that all the investigated alloys are hard ( 21 $\pm 2 \mathrm{GPa})$. The empirical ductility criteria developed by Pugh [47] 
and Pettifor [48] do not indicate enhanced toughness compared to the binary parent compounds $\mathrm{TiC}$ and VC. However, stress/strain results, corroborated by electronic structure analyses reveal facile formation of stacking faults during $\{111\}\langle 1 \overline{1} 0\rangle$ slip suggest improved plasticity for VMoC alloys. Electronic structure analyses also reveal electronic layering upon trigonal shearing which enables a selective hard/ductile response to tensile/shear stresses. Plasticity in VMoC is further supported by the similarities in the stress/strain curves of $\mathrm{VMoC}$ to those obtained for the corresponding cubic TM nitride VMoN, a hard ceramic which has been shown experimentally to be relatively ductile. Our results show promise for $\mathrm{VMoC}$ as a TM carbide alloy exhibiting both hardness and ductility, i.e. toughness.

\section{Acknowledgements}

We appreciate financial support from the Swedish Research Council (VR) Linköping Linnaeus Initiative LiLi-NFM (Grant \# 2008-6572) and the Swedish Government Strategic Research Area Grant in Materials Science on Advanced Functional Materials. Calculations were performed using the resources provided by the Swedish National Infrastructure for Computing (SNIC), on the Triolith Cluster located at the National Supercomputer Centre (NSC) in Linköping, and on the Abisko cluster located at the High Performance Computing Center North (HPC2N) in Umeå. D. G. S. gratefully acknowledges financial support from the Olle Engkvist Foundation. 


\section{References}

[1] H. Kindlund, D.G. Sangiovanni, L. Martínez-de-Olcoz, J. Lu, J. Jensen, J. Birch, I. Petrov, J.E. Greene, V. Chirita, L. Hultman, Toughness enhancement in hard ceramic thin films by alloy design, APL Mater. 1 (2013) 042104. doi:doi:10.1063/1.4822440.

[2] R. Hauert, J. Patscheider, From Alloying to Nanocomposites-Improved Performance of Hard Coatings, Adv. Eng. Mater. 2 (2000) 247-259. doi:10.1002/(SICI)1527-2648(200005)2:5<247::AID-ADEM247>3.0.CO;2-U.

[3] J.-E. Ståhl, SECO Tools AB, eds., Metal cutting: theories and models, Univ., Div. of Production and Materials Engineering, Lund, 2012.

[4] L.E. Toth, Transition metal carbides and nitrides, Academic Press, 1971.

[5] S. Veprek, M.G.J. Veprek-Heijman, P. Karvankova, J. Prochazka, Different approaches to superhard coatings and nanocomposites, Thin Solid Films. 476 (2005) 1-29. doi:10.1016/j.tsf.2004.10.053.

[6] L. Hultman, J. Bareño, A. Flink, H. Söderberg, K. Larsson, V. Petrova, M. Odén, J.E. Greene, I. Petrov, Interface structure in superhard TiN-SiN nanolaminates and nanocomposites: Film growth experiments and ab initio calculations, Phys. Rev. B. 75 (2007) 155437. doi:10.1103/PhysRevB.75.155437.

[7] P.H. Mayrhofer, C. Mitterer, J.G. Wen, J.E. Greene, I. Petrov, Self-organized nanocolumnar structure in superhard TiB2 thin films, Appl. Phys. Lett. 86 (2005) 131909. doi:10.1063/1.1887824.

[8] C.-S. Shin, D. Gall, N. Hellgren, J. Patscheider, I. Petrov, J.E. Greene, Vacancy hardening in single-crystal $\mathrm{TiN}_{\mathrm{x}}(001)$ layers, J. Appl. Phys. 93 (2003) 6025-6028. doi:10.1063/1.1568521.

[9] S.-H. Jhi, S.G. Louie, M.L. Cohen, J. Ihm, Vacancy Hardening and Softening in Transition Metal Carbides and Nitrides, Phys. Rev. Lett. 86 (2001) 3348-3351. doi:10.1103/PhysRevLett.86.3348.

[10] C.-S. Shin, S. Rudenja, D. Gall, N. Hellgren, T.-Y. Lee, I. Petrov, J.E. Greene, Growth, surface morphology, and electrical resistivity of fully strained substoichiometric epitaxial $\operatorname{TiNx}(0.67 \leqslant x<1.0)$ layers on $\mathrm{MgO}(001)$, J. Appl. Phys. 95 (2004) 356-362. doi:10.1063/1.1629155.

[11] C.-S. Shin, D. Gall, Y.-W. Kim, P. Desjardins, I. Petrov, J.E. Greene, M. Odén, L. Hultman, Epitaxial $\mathrm{NaCl}$ structure $\delta$-TaNx(001): Electronic transport properties, elastic modulus, and hardness versus N/Ta ratio, J. Appl. Phys. 90 (2001) 28792885. doi:10.1063/1.1391214.

[12] H. Kindlund, D.G. Sangiovanni, J. Lu, J. Jensen, V. Chirita, J. Birch, I. Petrov, J.E. Greene, L. Hultman, Vacancy-induced toughening in hard single-crystal $\mathrm{V}_{0.5} \mathrm{Mo}_{0.5} \mathrm{~N}_{\mathrm{x}} / \mathrm{MgO}\left(\begin{array}{lll}0 & 0 & 1\end{array}\right)$ thin films, Acta Mater. 77 (2014) 394-400. doi:10.1016/j.actamat.2014.06.025.

[13] S.-H. Jhi, J. Ihm, S.G. Louie, M.L. Cohen, Electronic mechanism of hardness enhancement in transition-metal carbonitrides, Nature. 399 (1999) 132-134. doi:10.1038/20148.

[14] H.W. Hugosson, U. Jansson, B. Johansson, O. Eriksson, Restricting Dislocation Movement in Transition Metal Carbides by Phase Stability Tuning, Science. 293 (2001) 2434-2437. doi:10.1126/science.1060512.

[15] T. Joelsson, L. Hultman, H.W. Hugosson, J.M. Molina-Aldareguia, Phase stability tuning in the $\mathrm{Nb}_{\mathrm{x}} \mathrm{Zr}_{1-\mathrm{x}} \mathrm{N}$ thin-film system for large stacking fault density and 
enhanced mechanical strength, Appl. Phys. Lett. $86 \quad$ (2005) 131922. doi:10.1063/1.1884743.

[16] W.K. Tredway, MATERIALS SCIENCE:Toughened Ceramics, Science. 282 (1998) 1275-1275. doi:10.1126/science.282.5392.1275.

[17] W.J. Clegg, MATERIALS SCIENCE:Enhanced: Controlling Cracks in Ceramics, Science. 286 (1999) 1097-1099. doi:10.1126/science.286.5442.1097.

[18] A.H. Sherry, T.J. Marrow, 1.04 - Mechanical Properties and Fracture of Materials, in: B. Cottis, M. Graham, R. Lindsay, S. Lyon, T. Richardson, D. Scantlebury, H. Stott (Eds.), Shreirs Corros., Elsevier, Oxford, 2010: pp. 77-88. http://www.sciencedirect.com/science/article/pii/B9780444527875000056 (accessed November 19, 2013).

[19] D.P.H. Hasselman, Unified Theory of Thermal Shock Fracture Initiation and Crack Propagation in Brittle Ceramics, J. Am. Ceram. Soc. 52 (1969) 600-604. doi:10.1111/j.1151-2916.1969.tb15848.x.

[20] D.G. Sangiovanni, V. Chirita, L. Hultman, Electronic mechanism for toughness enhancement in $\mathrm{Ti}_{\mathrm{x}} \mathrm{M}_{1-\mathrm{x}} \mathrm{N}$ (M=Mo and W), Phys. Rev. B. 81 (2010) 104107. doi:10.1103/PhysRevB.81.104107.

[21] D.G. Sangiovanni, L. Hultman, V. Chirita, Supertoughening in B1 transition metal nitride alloys by increased valence electron concentration, Acta Mater. 59 (2011) 2121-2134. doi:10.1016/j.actamat.2010.12.013.

[22] D. Edström, D.G. Sangiovanni, L. Hultman, V. Chirita, Effects of atomic ordering on the elastic properties of TiN- and VN-based ternary alloys, Thin Solid Films. 571 (2014) 145-153. doi:10.1016/j.tsf.2014.09.048.

[23] H. Kindlund, J. Lu, J. Jensen, I. Petrov, J.E. Greene, L. Hultman, Epitaxial $\mathrm{V}_{0.6} \mathrm{~W}$ $0.4 \mathrm{~N} / \mathrm{MgO}(001)$ : Evidence for ordering on the cation sublattice, J. Vac. Sci. Technol. Vac. Surf. Films. 31 (2013) 040602. doi:10.1116/1.4807654.

[24] D.J. Rowcliffe, G.E. Hollox, Hardness anisotropy, deformation mechanisms and brittle-to-ductile transition in carbide, J. Mater. Sci. 6 (n.d.) 1270-1276. doi:10.1007/BF00552040.

[25] S. Kiani, J.-M. Yang, S. Kodambaka, Nanomechanics of Refractory TransitionMetal Carbides: A Path to Discovering Plasticity in Hard Ceramics, J. Am. Ceram. Soc. 98 (2015) 2313-2323. doi:10.1111/jace.13686.

[26] G. Kresse, J. Hafner, Ab initio molecular dynamics for liquid metals, Phys. Rev. B. 47 (1993) 558-561. doi:10.1103/PhysRevB.47.558.

[27] J.P. Perdew, K. Burke, M. Ernzerhof, Generalized Gradient Approximation Made Simple, Phys. Rev. Lett. 77 (1996) 3865-3868. doi:10.1103/PhysRevLett.77.3865.

[28] P.E. Blöchl, Projector augmented-wave method, Phys. Rev. B. 50 (1994) 1795317979. doi:10.1103/PhysRevB.50.17953.

[29] H.J. Monkhorst, J.D. Pack, Special points for Brillouin-zone integrations, Phys. Rev. B. 13 (1976) 5188-5192. doi:10.1103/PhysRevB.13.5188.

[30] A.B. Mei, O. Hellman, N. Wireklint, C.M. Schlepütz, D.G. Sangiovanni, B. Alling, A. Rockett, L. Hultman, I. Petrov, J.E. Greene, Dynamic and structural stability of cubic vanadium nitride, Phys. Rev. B. 91 (2015). doi:10.1103/PhysRevB.91.054101.

[31] L.F. Mattheiss, D.R. Hamann, Bulk and surface electronic structure of hexagonal WC, Phys. Rev. B. 30 (1984) 1731-1738. doi:10.1103/PhysRevB.30.1731.

[32] A. Zunger, S.-H. Wei, L.G. Ferreira, J.E. Bernard, Special quasirandom structures, Phys. Rev. Lett. 65 (1990) 353-356. doi:10.1103/PhysRevLett.65.353. 
[33] B. Alling, A.V. Ruban, A. Karimi, O.E. Peil, S.I. Simak, L. Hultman, I.A. Abrikosov, Mixing and decomposition thermodynamics of $\mathrm{c}-\mathrm{Ti} 1-\mathrm{x} \mathrm{Al}$ x N from first-principles calculations, Phys. Rev. B. 75 (2007). doi:10.1103/PhysRevB.75.045123.

[34] D.A. Porter, K.E. Easterling, M. Sherif, Phase Transformations in Metals and Alloys, Third Edition (Revised Reprint), CRC Press, 2009.

[35] F. Tasnádi, M. Odén, I.A. Abrikosov, Ab initio elastic tensor of cubic $\operatorname{Ti}_{0.5} \mathrm{Al}_{0.5} \mathrm{~N}$ alloys: Dependence of elastic constants on size and shape of the supercell model and their convergence, Phys. Rev. B. $85 \quad$ (2012) 144112. doi:10.1103/PhysRevB.85.144112.

[36] R. Hill, The Elastic Behaviour of a Crystalline Aggregate, Proc. Phys. Soc. Sect. A. 65 (1952) 349-354. doi:10.1088/0370-1298/65/5/307.

[37] P.H. Mayrhofer, D. Music, J.M. Schneider, Influence of the Al distribution on the structure, elastic properties, and phase stability of supersaturated Ti[sub 1-x]Al[sub x]N, J. Appl. Phys. 100 (2006) 094906. doi:10.1063/1.2360778.

[38] R.S. Irani, R.W. Cahn, The mechanism of crystallographic ordering in CuPt, J. Mater. Sci. 8 (1973) 1453-1472. doi:10.1007/BF00551670.

[39] F. Tian, J. D’Arcy-Gall, T.-Y. Lee, M. Sardela, D. Gall, I. Petrov, J.E. Greene, Epitaxial $\mathrm{Ti}_{1-\mathrm{x}} \mathrm{W}_{\mathrm{x}} \mathrm{N}$ alloys grown on $\mathrm{MgO}(001)$ by ultrahigh vacuum reactive magnetron sputtering: Electronic properties and long-range cation ordering, J. Vac. Sci. Technol. Vac. Surf. Films. 21 (2003) 140-146. doi:10.1116/1.1525818.

[40] A. Simůnek, How to estimate hardness of crystals on a pocket calculator, Phys. Rev. B. 75 (2007) 172108. doi:10.1103/PhysRevB.75.172108.

[41] W.B. Pearson, The Chrystal Chemistry and Physics of Metals and Alloys., Wiley, New York, NY, 1972.

[42] X.-Q. Chen, H. Niu, D. Li, Y. Li, Modeling hardness of polycrystalline materials and bulk metallic glasses, Intermetallics. 19 (2011) 1275-1281. doi:10.1016/j.intermet.2011.03.026.

[43] Y. Tian, B. Xu, Z. Zhao, Microscopic theory of hardness and design of novel superhard crystals, Int. J. Refract. Met. Hard Mater. 33 (2012) 93-106. doi:10.1016/j.ijrmhm.2012.02.021.

[44] D.G. Sangiovanni, F. Tasnádi, L. Hultman, I. Petrov, J.E. Greene, V. Chirita, N and Ti adatom dynamics on stoichiometric polar TiN(111) surfaces, Surf. Sci. 649 (2016) 72-79. doi:10.1016/j.susc.2016.01.031.

[45] D.G. Sangiovanni, L. Hultman, V. Chirita, I. Petrov, J.E. Greene, Effects of phase stability, lattice ordering, and electron density on plastic deformation in cubic TiWN pseudobinary transition-metal nitride alloys, Acta Mater. 103 (2016) 823-835. doi:10.1016/j.actamat.2015.10.039.

[46] H.X. Ji, C.C. Amato-Wierda, Chemical vapor deposition of Ti-W-C thin films, Surf. Coat. Technol. 148 (2001) 262-267. doi:10.1016/S0257-8972(01)01342-1.

[47] S.F. Pugh, XCII. Relations between the elastic moduli and the plastic properties of polycrystalline pure metals, Philos. Mag. Ser. 7. 45 (1954) 823-843. doi:10.1080/14786440808520496.

[48] D.G. Pettifor, Theoretical predictions of structure and related properties of intermetallics, Mater. Sci. Technol. 8 (1992) 345-349.

[49] R.H.J. Hannink, D.L. Kohlstedt, M.J. Murray, Brittle-Region Slip Systems in the Transition-Metal Carbides, Phys. Status Solidi A. 6 (1971) K25-K28. doi:10.1002/pssa.2210060146. 
[50] R.H.J. Hannink, D.L. Kohlstedt, M.J. Murray, Slip System Determination in Cubic Carbides by Hardness Anisotropy, Proc. R. Soc. Math. Phys. Eng. Sci. 326 (1972) 409-420. doi:10.1098/rspa.1972.0017.

[51] T. Fu, X. Peng, C. Huang, D. Yin, Q. Li, Z. Wang, Molecular dynamics simulation of VN thin films under indentation, Appl. Surf. Sci. 357, Part A (2015) 643-650. doi:10.1016/j.apsusc.2015.09.024.

[52] D.G. Sangiovanni, V. Chirita, L. Hultman, Toughness enhancement in TiAlN-based

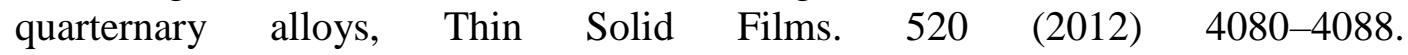
doi:10.1016/j.tsf.2012.01.030. 